IDEAS IN ECLLGGY AND EVILUTION 6: 52-54, 2013

doi:10.4033/iee.2013.6.16.e

(C) 2013 The Author. (C) Ideas in Ecology and Evolution 2013

Received 23 September 2013; Accepted 21 October 2013

\title{
Editarial
}

\section{Creativity in the review of science}

\section{Christopher J. Lortie}

\section{C.J. Lortie (lortie@yorku.ca), Department of Biology, York University, Toronto, ON, Canada, M6S 2E2}

\section{Preamble}

Science is fundamentally a creative pursuit. At every step of the process, novel ideas that are useful to the scientific task at hand are employed-the very definition of creativity (Runco and Jaeger 2012). In a recent commentary on novelty and editorial peer review, it was proposed that novelty be abandoned as a criterion associated with decisions by editors to reject (Arnqvist 2013). I find this a challenging proposition for at least two reasons. Novelty is important. Editors are useful. I highly value the creative aspects of what we do. I do not restrict this assessment of novel and useful to the interpretation proposed by the authors but apply the search for this criterion to the application, visuals, statistics, and integration of different ideas that in their combination become novel like hybrid vigor. Importantly, creativity research is an extensive and well-established field. Training (Graham et al. 2012, Ha 2006, Scott et al. 2004), environment (Hunter et al. 2009), testing (Anderson et al. 2004, Kim 2008, Kuncel et al. 2007), and selfversus non-self ratings ( $\mathrm{Ng}$ and Feldman 2012) provide clear guidelines and opportunities for effectively using creativity in peer review. Ecological editors may be chasing novelty based on intuition, and I recognize that there is variation in editors just as there is in any set of reviews by external referees, but this does not, however, directly implicate the loss of novelty or creativity as an important consideration when reviewing. On the contrary, perhaps we should embrace it, improve how we evaluate it, formalize it, and place it in its appropriate context.

\section{Solutions}

Improving peer review has been discussed extensively (Allesina 2012, Couzin-Frankel 2013, Fox and Petchy 2010, Hauser and Fehr 2007, Lortie et al. 2007,
Scott 2007, Ware 2008). Transparency, accountability, and clear sets of guidelines are all needed (Scott 2007). Checklists associated with other elements of best science could be developed for fit or niche of each journal, including how it values and vets creativity. Overinterpretation bias by authors is very real (Arnqvist 2013, Charlton 2004, Jone 2009, Lortie and Dyer 1999). Nonetheless, self-reporting of creativity is on average more accurate than external assessments ( $\mathrm{Ng}$ and Feldman 2012). A sensible strategy would be to move some of this reporting from within the publication to the details associated with the submission. Imagine if authors did some of the review for editors and submitted this online. Friendly review and collaborative writing involve this level of introspection and dialogue. Formalize this similar to versioning tools such as GitHub and include it with the submission (Box 1). The authors could then self-report the novelty of the paper and briefly explain. This would make the job of the editor much easier and facilitate identification of true novelty versus over-interpretation. It would also simplify publications to some extent. Many evidencebased medicine journals have categories of textboxes to this effect in the final publication. Ecology and evolution could adopt similar approaches to reduce unnecessary interpretation included in the discussion and abstract, but still provide an easy mechanism for readers to access the creative highlights.

More broadly, I propose a broader shift to considering creativity instead of novelty, and actively applying this to peer review itself. Peer review has not changed much since its invention (Couzin-Frankel 2013). We should begin to be more creative in the review process itself (Davidoff 2006, Koonin et al. 2006), and editors are perfectly positioned to lead this initiativeparticularly because there is every indication that there is already some degree of 'experimentation' (Cooke and Lapointe 2012). Novelty is important. Editors are 
useful. Combine, and we have an opportunity to experiment with creativity in the peer-review process. Editors share similar values to all practitioners because all/most in ecology are also active, publishing scientists and face similar challenges with peer review. Editors also value speed of review and decisions (Grod et al. 2009). Consequently, more effective handling of novelty by authors, referees, and editors would accelerate review. Directly recognizing and rewarding creativity also enhances creativity (Byron and Khazanchi 2012). The importance of this feedback loop cannot be understated given that we value new ideas so heavily in ecology but so arbitrarily reward them via the peerreview tools currently employed. Using creativity instead of novelty also ensures that new ideas are anchored in either an immediately perceived use or anticipated long-term value. Admittedly, this is still a judgment. Decoupling the subjective assessment of new from useful provides editors and referees a far more nuanced capacity to evaluate submissions. If most ideas are not relatively new in ecology (Arnqvist 2013), creativity can still be realized via novel application and extension of existing ideas. We do not want to unduly reject these forms of science.

Finally and even more dramatically, peer review is always a continuum. Benefits, costs, time spent, novelty, and relative contributions by the various agents vary considerable from journal to journal and rejection to rejection (Calcagno et al. 2012). A more profound experiment would be 'all or none' in peer reviewing. All review external, crowd-sourced, and open (Aarssen and Lortie 2012). Creativity and discovery discussed and openly realized. Openness has been shown to increase creativity (Feist 1998, Mussel, et al. 2011), and closed reviewing therefore stagnates ideation. Propagation of novel ideas via social networking (Darling et al. 2013), pre-prints (Priem et al. 2012, Shuai et al. 2012), discussion (Shema et al. 2012), and collaborative reviews (i.e. PeerJ) are available to ecologists. Reviews are also a creative process - i.e. not only do we review to determine merit or fit with journal, but also we review to improve our science (Ware 2008). The best reviews are not only apt, but provide novel insights into one's own work. Under the 'all' model, editors simply pick up papers from pre-print repositories that have been reviewed, favourited, and discussed, and then invite the authors to submit to the journal. Then publish. None-to-limited reviews done in-house by journals. Some journals or subsets of publications within a journal could also be reviewed only by a paid, rotating editorial staff of active ecological researchers (also none in terms of external review). This is a highly effective and tightly-controlled set of submissions. It would be more rapid because a large proportion of reviews and manuscripts live (quite literally) in the online repositories available to editors but not directly in the formal system. In summary, reviewing for novelty may be leading ecologists astray insofar as it is closed, anchored only in the new, and not useful, neglects novel reviews, and fails to capitalize on all the online opportunities for creative dialog and review emerging. I agree that it may be time to rethink novelty in ecology, but I see creativity everywhere in what we do already-including peer review.

Box 1. Creative highlights of this idea experiment/commentary

\section{General propositions}

Replace novelty criterion in ecology with creativity.

Experiment with peer review.

Extent of peer review is always a continuum.

\section{Specific solutions}

Authors self rate novelty upon submission. Journals add highlight boxes for creativity populated by author/editor/referee comments. Crowd source all peer review openly.

Reserve editorial review for specific sets of papers.

\section{Author self-rating of creativity of this commentary}

This commentary was primarily a reply to the suggestion by Arnquist (2013) that we discard novelty as an element of editorial peer review in ecology and evolution. Alternative suggestions proposed and linkages to creativity research established.

\section{Literature cited}

Aarssen, L.W. and C.J. Lortie. 2012. Science Open Reviewed: An online community connecting authors with reviewers for journals. Ideas in Ecology and Evolution 5:78-83. CrossRef

Allesina, S. 2012. Modeling peer review: an agentbased approach. Ideas in Ecology and Evolution 5:27-35. CrossRef

Anderson, N., De Dreu, C.K.W., Carsten, K. and B.A. Nijstad. 2004. The routinization of innovation research: a constructively critical review of the stateof-the-science. Journal of Organizational Behavior 25:147-173. CrossRef

Arnqvist, G. 2013. Editorial rejects? Novelty, schnovelty! Trends in Ecology and Evolution 28:448-449. CrossRef

Byron, K. and S. Khazanchi. 2012. Rewards and creative performance: A meta-analytic test of 
theoretically derived hypotheses. Psyschological Bulletin 138:809-830. CrossRef

Calcagno, V., Demoinet, E., Gollner, K., Guidi, L. and C. de Mazancourt. 2012. Flows of research manuscripts among scientific journals reveal hidden submission patterns. Science: 23:1065-1069. CrossRef

Charlton, B.G. 2004. Why a journal of negative results? Journal of Negative Results 1:6-7.

Cooke, S. and N.W.R. Lapointe. 2012. Addressing editor(ial) malpractice in scientific journals. Ideas in Ecology and Evolution 5:84-92. CrossRef

Couzin-Frankel, J. 2013. Secretive and subjective, peer review proves resistant to study. Science 341:1331. CrossRef

Darling, E.S., Shiffman, D., Cote, I.M. and J.A. Drew. 2013. The role of twitter in the life cycle of a scientific publication. Ideas in Ecology and Evolution 6:32-43. CrossRef

Davidoff, F. 2006. Improving peer review: who's responsible? British Medical Journal 328:657-658.

Feist, G. J. 1998. A meta-analysis of personality in scientific and artistic creativity. Personality and Social Psychology Review 2:290-309. CrossRef

Fox, J. and O.L. Petchy. 2010. Pubcreds: fixing the peer review process by 'privatizing' the reviewer commons. Bulletin of the Ecological Society of America 91:325-333. CrossRef

Graham, S., McKeown, D., Kiuhara, S. and K.R. Harris. 2012. A meta-analysis of writing instruction for students in the elementary grades. Journal of Educational Psychology 104:879-896. CrossRef

Grod, O., Lortie, C.J. and A.E. Budden. 2009. Behind the shroud: a survey of editors in ecology and evolution. Frontiers in Ecology \& the Environment 8:187-192. CrossRef

Ha, H.H. 2006. A synthetic analysis of the effectiveness of single components and packages in creativity training programs. Creativity Research Journal 18:435-446. CrossRef

Hauser, M. and E. Fehr. 2007. An incentive solution to the peer review problem. Plos Biology 5:e107. CrossRef

Hunter, S.T., Bedell, K.E. and M.D. Mumford. 2009. Climate for creativity: A quantitative review. Creativity Research Journal 19:69-90. CrossRef

Jone, N. 2009. Sneak test shows positive-paper bias. Nature CrossRef

Kim, K.H. 2008. Meta-analyses of the relationship of creative achievement to both IQ and divergent thinking test scores. Journal of Creative Behavior 42:106-130. CrossRef
Koonin, E.V., Landweber, L.F. and D.J. Lipman. 2006. A community experiment with fully open and published peer review. Biology Direct 1:1-3. CrossRef

Kuncel, N.R., Crede, M. and L.L. Thomas. 2007. A meta-analysis of the predictive validity of the Graduate Management Admission Test (GMAT) and Undergraduate Grade Point Average (UGPA) for graduate student academic performance. Academy of Management Learning and Education 6:51-68. CrossRef

Lortie, C.J., Aarssen, L.W., Budden, A.E., Koricheva, J., Leimu, R. and T. Tregenza. 2007. Publication bias and merit in ecology. Oikos 116:1247-1253. CrossRef

Lortie, C.J. and Dyer, A.R. 1999. Over-interpretation: avoiding the stigma of non-significant results. Oikos 87:183-184. CrossRef

Mussel, P., Winter, C., Gelleri, P. and H. Schuler. 2011. Explicating the openness to experience construct and its subdimensions and facets in a work setting. International Journal of Selection and Assessment 19:145-156. CrossRef

$\mathrm{Ng}, \mathrm{T}$. and D.C. Feldman. 2012. A comparison of selfratings and non-self-report measures of employee creativity. Human Relations 65:1021-1047. CrossRef

Priem, J., Piwowar, H. and B.M. Hemminger. 2012. Altmetrics in the wild: using social media to explore scholarly impact. arXiv $1203.4745 \mathrm{v} 1$.

Runco, M.A. and G.J. Jaeger. 2012. The standard definition of creativity. Creativity Research Journal 24:92-96. CrossRef

Scott, A. 2007. Peer review and the relevance of science. Futures 39:827-845. CrossRef

Scott, G., Leritz, L.E. and M.D. Mumford. 2004. The effectiveness of creativity training: A quantitative review. Creativity Research Journal 16:361-388. CrossRef

Shema, H., Bar-Ilan, J. and M. Thelwall. 2012. Research blogs and the discussion of scholarly information. PlosOne CrossRef

Shuai, X., Pepe, A. and J. Bollen. 2012. How the scientific community reacts to newly submitted preprints: Article downloads, Twitter mentions, and citations. arXiv: $1202.2461 v 1$.

Ware, M. 2008. Peer Review: benefits, perceptions and alternatives. Publishing Research Consortium, London. 